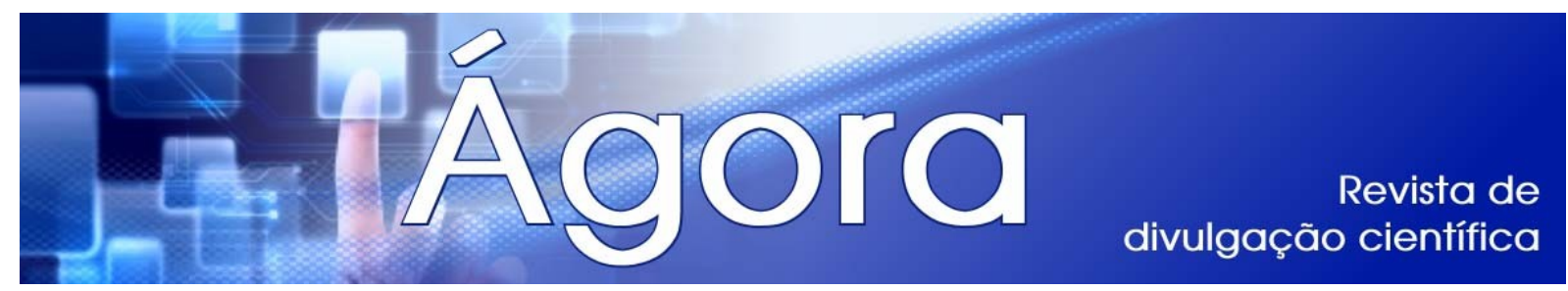

A VISÃO DOS PROFISSIONAIS CONTÁBEIS DE SANTA CATARINA SOBRE AS NOVAS NORMAS CONTÁBEIS ${ }^{1}$

\author{
Renan Caramori ${ }^{2}$ \\ Fernando Maciel Ramos ${ }^{3}$
}

\begin{abstract}
RESUMO: A pretensão pela criação de uma contabilidade semelhante internacionalmente é um grande objetivo da Ciência Contábil há muitos anos. Em 2005 , as normas internacionais de contabilidade deram um grande passo em busca da convergência mundial. A obrigatoriedade de seu uso pelas empresas listadas em bolsas da união europeia foi fundamental para dar propulsão ao projeto de harmonização contábil internacional, além de fomentar o interesse das demais organizações internacionais em se adequar aos novos parâmetros europeus. No Brasil, a adoção das IFRS começou em 2008 com as grandes companhias, sendo que em 2010 seu uso foi obrigatório para companhias de pequeno e médio porte. Diante deste recente contexto contábil, o presente estudo teve como objetivo analisar a percepção dos profissionais contábeis em relação às novas normas internacionais de contabilidade. Para atender a pesquisa, foi elaborado um questionário composto por 12 questões, posteriormente enviado aos 19.571 contadores de Santa Catarina com o auxílio do Conselho Regional de Contabilidade. Obteve-se retorno de 315 questionários, que foram analisados utilizando estatística descritiva. Com os resultados obtidos pode-se observar que a taxa de contadores insatisfeitos ou desatualizados sobre as novas regras contábeis ainda é um fator preocupante para a profissão.
\end{abstract}

Palavras chave: Contabilidade. International Financial Reporting Standards (IFRS). Harmonização Contábil.

ABSTRACT: The claim by creating a similar accounting internationally is a major goal of Accounting Science for many years. In 2005, the international accounting standards took a big step in search of global convergence. The mandatory use by companies listed on Union European purse was essential to give thrust to the project of international accounting harmonization, In addition to promoting the interest of other international organizations to adapt the new European parameters. In Brazil,

\footnotetext{
${ }^{1}$ Artigo científico resultante da Bolsa de Estudo e Pesquisa do Artigo 170, sob a orientação do Professor Fernando Maciel Ramos.

${ }^{2}$ Acadêmico do Curso de Ciências Contábeis da Universidade do Contestado - UnC/Campus Concórdia. Bolsista de Iniciação Científica do programa de pesquisa do artigo 170. E-mail: renancaramori@gmail.com.

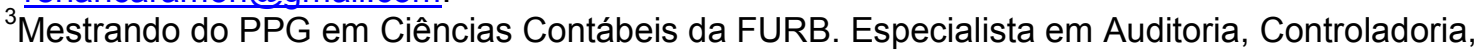
Perícia Contábil e Gerência Contábil. Prof. ${ }^{\circ}$ do curso de Ciências Contábeis da Universidade do Contestado - UnC/Campus Concórdia. E-mail: ramoss.cco@gmail.com.
}

Ágora: R. Divulg. Cient., v. 18, n. 2, p. 202-221, dez. 2011 (ISSN 2237-9010) 
the adoption of IFRS began in 2008 with large companies, and in 2010 its use was mandatory for companies small and medium sized. In front of this recent accounting context, the present study aimed to analyze the perceptions of accounting professionals in relation of the new international accounting standards. In response to the research, was developed a questionnaire consisting of 12 questions, before sent to 19,571 meters of Santa Catarina with the help of the Regional Accounting Council. With the return obtained of 315 questionnaires that were analyzed using descriptive statistics. With the results obtained can be seen that the rate of dissatisfied or outdated counters about the new accounting rules is still a worrying factor for the profession.

Keywords: Accounting. International Financial Reporting Standards (IFRS). Accounting Harmonization.

\section{INTRODUÇÃO}

A contabilidade exerce papel fundamental para todas as entidades, bem como para seus administradores, colaboradores, investidores, instituições financeiras e principalmente para o Fisco. Seus resultados sempre estão sendo analisados e avaliados de alguma maneira por estes usuários. Sendo assim, surge a necessidade de estar adaptando a legislação vigente, para que os resultados obtidos reflitam de forma positiva para a entidade.

No atual cenário em que a contabilidade se encontra, é extremamente necessária a atualização do profissional contábil, pois atualmente os contadores vivenciam a homogeneização das normas internacionais de contabilidade, conhecidas como International Financial Reporting Standards (IFRS).

Neste atual âmbito contábil, um dos grandes e visíveis obstáculos do Brasil é a escassez de profissionais hábeis, aptos e competentes em IFRS. Neste contexto a pesquisa ocupa-se da seguinte problemática: "Qual a visão dos contadores de Santa Catarina sobre a adoção das normas internacionais de contabilidade?".

Diante dessa implicação, a presente pesquisa teve como objetivo principal pesquisar a percepção dos profissionais da área contábil quanto às novas normas brasileiras de contabilidade, e com isso, identificar o grau de informação e atualização dos contadores catarinenses. 
Este estudo justifica-se pela necessidade de conhecer o pensamento e contribuições das novas normas contábeis para os profissionais e empresas do estado de Santa Catarina, diante de mudanças tão recentes e profundas na área.

O presente artigo está disposto em cinco seções, sendo inicialmente exibidos os aspectos introdutórios, que indicam o problema, os objetivos e a justificativa do estudo. Em seguida, efetuou-se uma revisão teórica, contendo pesquisas correlacionadas com o tema deste artigo. Posteriormente encontram-se os aspectos sobre a metodologia utilizada, seguida da análise dos dados coletados que indicam qual a impressão e assimilação que os profissionais têm sobre as IFRS, finalizando com as conclusões adquiridas na pesquisa.

\section{PROFISSÃO CONTÁBIL}

A contabilidade representa atualmente um papel de extrema importância para as organizações de todos os setores. É ela a responsável pela descrição da situação empresarial, que evidencia as melhores decisões a serem tomadas.

A ciência contábil está presente desde os primórdios da evolução humana, segundo Nagatsuka e Teles (2005), a contabilidade é tão antiga quanto o homem. De acordo com Sá (2002), ela era utilizada pelos homens primitivos que faziam inscrições através de desenhos, demonstrando sua riqueza. Os registros foram ficando complexos, tanto que os Sumero-Babilônios usavam pedaços de argilas nas inscrições. No Egito, o "papiro" originou os livros contábeis, onde eram feitos os registros. A invenção da escrita aprimorou o sistema de registros. Alguns estudiosos ainda afirmam que foi a escrita contábil que originou a escrita comum, e não o contrário disso.

Com a evolução da contabilidade se fez necessário que os profissionais adquirissem conhecimentos técnicos, além do estabelecimento de normas que regulamentassem a profissão.

No Brasil, já se encontravam profissionais de contabilidade no início da colonização. A primeira nomeação para contador geral e guarda-livros ocorreu em 1549, por D. João III. No entanto, apenas em 1770 surge a primeira regulamentação contábil no Brasil, quando Dom José, rei de Portugal, expede uma carta de Lei a todos os países colonizados (COELHO, 2002). 
Coelho (2002) cita ainda que a primeira regulamentação contábil em território nacional ocorreu em 1870, através do reconhecimento oficial da Associação dos Guarda-Livros da Corte, pelo Decreto Imperial $n^{\circ} 4.475$, representando um marco para a profissão, pois distingue o guarda-livros como a primeira profissão liberal regulamentada do Brasil.

Vicenzo Mazi, em 1923, foi o primeiro a definir o patrimônio como objeto da contabilidade, não servindo apenas para registrar informações, mas também, como instrumento básico de gestão (ZANLUCA, 2009).

O profissional formado em contabilidade exerce a função de registro, orientação e controle das organizações. É ele o encarregado pelos assuntos referentes a situação da riqueza das empresas (SÁ, 1998).

Qualquer empresa, por menor que seja, necessita de um profissional contábil. O contador é fonte imprescindível para a tomada de decisões da organização. O papel de orientador é a sua mais destacada função, apresentando alternativas para que as organizações tenham um melhor desempenho (SÁ, 1998).

Reconhecendo a importância que a profissão contábil tem perante as organizações, Jacques Chirac (1997 apud CARVALHO, 2012, p.1), ex-presidente da França, fez o seguinte discurso no XV congresso mundial de contadores:

\footnotetext{
Profissão contábil desempenha um papel fundamental, na modernização e internacionalização de nossa economia. Isso porque não se restringem a cuidar de contas. Vocês são conselheiros e, às vezes, confidentes da administração de companhia, para que têm um importante papel a desempenhar, especialmente em assuntos sociais e tributários. Vocês orientam pequenas e médias empresas e sua administração, simplificando as alternativas, que ainda são demasiadas e complexas. Vocês desempenham portanto, um papel no desenvolvimento das possibilidades de emprego que merece um especial registro de reconhecimento.
}

São duas possíveis formações na área: como técnico de contabilidade, com curso de nível técnico, e como contador, concluindo o curso de nível superior em Ciências Contábeis.

O formando em contabilidade encontra um vasto campo de atuação. Segundo Marion (2005) a área contábil é uma das que mais oportunizam possibilidades de trabalho. As alternativas são inúmeras, de acordo com a Resolução CFC n 560, de 28 de outubro de 1983, são elas: analista, assessor, assistente, auditor externo ou interno, conselheiro, consultor, controlador de arrecadação, "controller", educador, 
escritor ou articulista técnico, escriturador contábil ou fiscal, executor subordinado, fiscal de tributos, legislador, organizador, perito, pesquisador, planejador, professor ou conferencista e redator.

Nas últimas décadas a profissão contábil vem ganhando destaque e se modificando constantemente. A progressiva mudança na área instigou ainda mais a atualização dos profissionais. Nesse sentido, Roberto Aurélio de Merlo (2008) destaca que o profissional contábil de sucesso será aquele que se mantiver a par da evolução das relações de mercado, fomentada pelo progresso da globalização. $O$ mesmo deverá aliar-se ao constante avanço da tecnologia da informação e comunicação, contribuindo assim para uma atividade empresarial dinâmica e eficaz.

\section{ADOÇÃO DAS NORMAS INTERNACIONAIS DE CONTABILIDADE}

A harmonização das normas internacionais de contabilidade é um dos assuntos mais destacados atualmente no cenário contábil. Para se compreender a nova regularização, deve-se primeiramente compreender o conceito de harmonização.

Luft (2000, p.365) destaca: "Harmonizar: tornar harmônico; conciliar; congraçar; estar em harmonia”. A harmonização contábil pode ser interpretada como um processo, de acordo entre diversos países, que conserva as especificidades de cada padrão contábil, mas permite uma elasticidade, tornando-os conciliáveis e facilitando a troca de informações.

Entretanto, não pode-se confundir o termo "harmonização" com "padronização". Padronizar, segundo Luft (2000, p.496) é "estabelecer o padrão de; dar uma feição comum, típica, segundo um modelo escolhido". Dessa forma, entende-se que a padronização contábil somente existirá no momento em que os padrões serão totalmente uniformizados, sem elasticidade alguma.

A padronização visa ter regras uniformes e inflexíveis. A harmonização quer obter uma linguagem contábil internacional, considerando as características de cada região e compreendendo a diversidade entre culturas e legislações.

Esse grande empenho pela harmonização contábil surgiu graças ao esforço de diversos organismos internacionais e nacionais envolvidos neste processo. Atualmente, as IFRS são regulamentadas pelo International Accounting Standrads 
Board - IASB, conhecido como o Colegiado de padrões contábeis, que é subdividido em colegiado de normas internacionais de contabilidade, colegiado de interpretações, e conselho assessor de padrões. Segundo Niyama (2009) o IASB tem feito um esplêndido trabalho na edição e atualização das normas internacionais, incentivando entidades e reguladores de normas contábeis no intuito de compreenderem os benefícios da mesma.

O IASC era o antecessor do IASB. Dele vários organismos internacionais se associaram, entre eles o IFAC (International Federation of Accounting Committee) que objetiva-se em desenvolver a profissão e harmonizar padrões contábeis mundiais; o IOSCO (International Organization of Securities Commission) que é responsável pela regulação de grande parte do mercado de capitais no planeta; além da comunidade europeia, grupo do G7 e Fundo Monetário Internacional.

Existem ainda outros organismos internacionais que muito contribuíram para a convergência contábil internacional, dentre eles estão o ISAR (Intergovernamental Working of Experts on International Standards of Accounting and Reporting), que foi gerado para analisar os impactos que as grandes companhias multinacionais produziam nas relações internacionais, e o FASB (Financial Accounting Standards Board), que é o órgão responsável pela regulamentação contábil nos Estados Unidos.

No Brasil, em 2005 foi criado o Comitê de Pronunciamentos Contábeis CPC, que segundo o Conselho Federal de Contabilidade, pela resolução $\mathrm{N}^{\circ}$ 1.055/05 é composto por: ABRASCA (Associação Brasileira das Companhias Abertas); APIMEC NACIONAL (Associação dos Analistas e Profissionais de Investimento do Mercado de Capitais); BOVESPA (Bolsa de Valores de São Paulo); CFC (Conselho Federal de Contabilidade); IBRACON (Instituto dos Auditores Independentes do Brasil); e FIPECAFI (Fundação Instituto de Pesquisas Contábeis, Atuarias e Financeiras). A mesma resolução ainda define o principal objetivo do $\mathrm{CPC}$, que é o de estudar, preparar, emitir e divulgar pronunciamentos técnicos sobre procedimentos e informações contábeis, levando em conta a convergência internacional das normas contábeis.

A pretensão pela criação de uma contabilidade semelhante internacionalmente é um grande objetivo da Ciência Contábil há muito tempo. Em 1904, durante o Primeiro Congresso Internacional de Contadores, o assunto já era 
referência. No entanto, essa pressão por uma contabilidade harmonizada foi intensificada ultimamente.

O anseio de organizar os métodos e procedimentos contábeis começou individualmente com obras que ensinavam a registrar, mas alcançou seu apogeu na primeira metade do século XIX, após a introdução do conhecimento contábil no campo da ciência. Nessa época, iniciaram-se as tentativas de universalização das normas e procedimentos contábeis. Entretanto, foi na segunda metade do século XIX que com maior aplicação se realizou um movimento normativo, composto de entidades de classe contábil e as maiores companhias de serviços do ramo nos países democráticos. (SÁ, 2009).

A crescente evolução da competitividade, a rapidez dos negócios e a dependência de relações no exterior instigaram muitos profissionais de Contabilidade em realizar profundas mudanças no âmbito internacional. Além desses fatores, a ampla divergência contábil no mundo ressaltava a relevância de se harmonizar tais normas. De acordo com Wyatt e Yospe, citados por Choi e Levichi (1994), demonstrações contábeis diferentes levam a dificuldades de compreensão e interpretação, quando os dados contábeis de uma determinada localidade são preparados pela sua regulamentação e utilizados por pessoas que seguem outros padrões.

Pohlmann (1995 apud SOUZA; COUTINHO FILHO, 2007) argumenta que é necessário o processo de harmonização internacional das normas contábeis, já que é perceptível a constante globalização dos negócios, que requer métodos e processos uniformes das demonstrações contábeis, capazes de serem compreendidas por todos aqueles que a utilizam.

Em 2005 as novas normas contábeis foram introduzidas na Europa, de forma obrigatória para todas as companhias abertas. No Brasil, em dezembro de 2007 foi efetivada a edição da lei $n^{\circ} 11.638$, que começou a vigorar a partir de $1^{\circ}$ de janeiro de 2008, determinando que as grandes companhias em território brasileiro fossem as primeiras organizações obrigadas a implantarem as IFRS em seu sistema contábil. Dois anos depois, as pequenas e médias empresas foram subordinadas a seguirem um modelo simplificado das IFRS. O Comitê de Pronunciamentos Contábeis (2008) menciona a convergência normativa ocorrida no Brasil, a lei $n^{\circ}$ 11.638, publicada em 28/12/2007, alterada posteriormente pela Medida Provisória ${ }^{\circ}$ 
449, de dezembro de 2008, modificou consideravelmente o ramo contábil da Lei das sociedades por ações, de 1976, que permitiu a convergência das normas brasileiras para as normas internacionais de contabilidade.

Lisboa (1998 apud JUNIOR, 2008, p.3) cita as principais vantagens, desvantagens e obstáculos referentes à harmonização contábil:

\begin{abstract}
Vantagens: comparabilidade na avaliação do desempenho de empresas em nível mundial; maior facilidade para o ensino da contabilidade, maior facilidade para transferência de pessoal entre as subsidiárias de uma multinacional; maior facilidade para o acesso das empresas a recursos financeiros internacionais; permite harmonização de pré-requisitos para que as empresas possam ter seus papeis negociados em diferentes bolsas de valores.

Desvantagens: não reconhece que diferentes países precisam de normas diferentes, de acordo às suas especificidades culturais legais e econômicas; a harmonização implica na redução de opções de práticas contábeis bem fundamentadas.

Obstáculos: o alto grau das diferenças entre as normas e práticas contábeis dos diversos países, de entidades de profissionais com poder de influência e nacionalismo.
\end{abstract}

Nesse processo de adaptação são inúmeras as dificuldades. A escassez de profissionais hábeis em IFRS e a grande divergência contábil formam ainda grandes obstáculos. Já dentre os vários benefícios, Marchesini (2008) destaca a facilidade de acesso das empresas a recursos financeiros internacionais, afirmando que a nova regulamentação contábil trará mais investimentos oriundos do exterior para o Brasil, uma vez que eles já desfrutam dessas novas práticas contábeis.

\title{
ESTUDOS CORRELACIONADOS
}

No presente estudo, utilizou-se a compreensão de teorias e aplicações de pesquisas para o entendimento das normas internacionais de contabilidade. Estes estudos anteriores contribuíram no curso da pesquisa, na compreensão do tema e na rota dos objetivos.

Souza e Coutinho Filho (2007) realizaram uma pesquisa intitulada "Harmonização Internacional: Um estudo sobre as dificuldades de convergência das normas contábeis brasileiras em relação as normas internacionais de contabilidade (IFRS)" na qual investigam as principais dificuldades de adaptação das normas internacionais de contabilidade em uma empresa metalúrgica do Norte de Minas. A 
metodologia utilizada se baseava em estudo de caso, contendo uma entrevista semiestruturada e questionários, além de análise documental e da observação.

Concluindo o trabalho, observou-se que a empresa em questão está integrada no contexto contábil internacional, no entanto as novas normas apresentam poucas semelhanças com aquelas que existiam anteriormente, gerando significativas diferenças nos resultados. Algumas dificuldades foram bastante evidentes. A escassez de profissionais hábeis em IFRS contribuiu para as dificuldades de compreensão das novas normas. Outro aspecto que favoreceu a dificuldade de adesão das normas foi o sistema jurídico brasileiro, que é extremamente formalista. A cultura é outra característica destacada no trabalho, apesar de não afetar muito a empresa estudada no decorrer da pesquisa, pelo fato de essa ser uma multinacional.

No Simpósio de Excelência em Gestão e Tecnologia - SEGeT (2008) apresentou-se um estudo realizado por Meirelles Junior (2009) com o propósito de esclarecer questões referentes as novas normas internacionais, objetivando-se a explicar o processo de criação e harmonização das IFRS. O trabalho foi nomeado como "Harmonização das normas internacionais de contabilidade".

A pesquisa conclui que um dos desafios na adoção das normas é alcançar a consistência no entendimento e aplicação das mesmas. No entanto, observa-se que a harmonização contábil é estritamente necessária. Devido as diferenças culturais existentes, constantemente haverá particularidades que deverão ser toleradas, sempre seguindo os Princípios Fundamentais de Contabilidade.

Já Costa, Campos e Amaral (2009) em sua pesquisa, "Capacitação profissional: um estudo sobre a adoção das Normas Internacionais de Contabilidade (IFRS) nas instituições particulares de ensino superior do $A B C$ " busca investigar se as Instituições Particulares de Ensino Superior do $A B C$ estão preparadas para capacitar o profissional contábil a trabalhar conforme os padrões impostos pelas IFRS, e se os professores da área contábil estão adequadamente preparados para exercer suas atividades em relação a esse assunto.

Ao final da pesquisa, se conclui que as instituições analisadas demonstram não estar aptas a ministrar aulas de Ciências Contábeis conforme os padrões exigidos pelas IFRS, necessitando que ocorra a atualização dos professores, de modo que eles sejam capacitados a lecionar suas disciplinas conforme as novas 
regras. Observa-se ainda que há necessidade em elaborar planos estratégicos que conciliem o curso de Ciências Contábeis de acordo com os padrões contábeis internacionais (COSTA, MENDES DE CAMPOS E AMARAL, 2009).

Avelino, Santana, Colauto e Madeira (2010) realizaram um estudo, denominado "Análise do perfil dos estudantes em Ciências Contábeis e sua relação com o processo de convergências das normas contábeis" com o objetivo de verificar se os estudantes da área contábil estão se preparando para a convergência das Normas Brasileiras de Contabilidade aos padrões internacionais. O método de pesquisa contou com um estudo exploratório por meio da execução de questionário, com estudantes do curso de Ciências Contábeis de uma instituição federal do estado de Minas Gerais.

Concluindo o trabalho, o que se verifica é que os estudantes de Ciências Contábeis estão conscientes das atuais mudanças e das necessidades do mercado, assim estão buscando alternativas para se manter atualizados, desenvolvendo um perfil profissional diferenciado, sendo mais dinâmicos, multidisciplinares e flexíveis (AVELINO, SANTANA, COLAUTO E MADEIRA, 2010).

$\mathrm{Na}$ próxima seção apresenta-se a metodologia e ferramenta utilizada para realização desta pesquisa.

\section{MATERIAL E MÉTODOS}

Defronte aos vários tipos de pesquisa existentes, Collis e Hussey (2005) mencionam que estas podem ser classificadas de acordo com seu objetivo, quanto ao processo e lógica de pesquisa e ainda quanto ao resultado da mesma.

Collis e Hussey, (2005), corroboram mencionando que a pesquisa descritiva é a qual descreve o comportamento dos fenômenos, indo além da pesquisa exploratória, pois procura avaliar e descrever as características do objeto de estudo.

A respeito dos procedimentos, caracteriza-se como pesquisa survey, conhecida como levantamento. Os dados foram coletados mediante um questionário eletrônico (Google $®$ Docs) composto por 12 questões, das quais todas eram de caráter fechado. $\mathrm{Na}$ primeira parte do questionário, procura-se caracterizar os respondentes, e na segunda parte, as perguntas são relativas à percepção, 
atualização e preparação dos profissionais de contabilidade sobre as novas normas contábeis.

Em relação aos respondentes, esses foram todos os contadores do estado de Santa Catarina, que segundo o Conselho Regional de Contabilidade (CRC), em 06 de dezembro de 2012 totalizam 19.571 profissionais. O contato com os respondentes se deu pelo correio eletrônico, mediante o auxílio do CRC, que expediu um email aos profissionais notificando a pesquisa e enviando o questionário. Dos questionários enviados obteve-se 315 respostas, o que corresponde a um grau de confiança de 95\%.

Para a análise de dados foi utilizada estatística descritiva, a qual procura somente descrever e analisar os entrevistados, sem que haja qualquer conclusão ou interferência por parte do pesquisador. Os dados foram analisados através de percentual e número de respostas iguais.

No próximo segmento serão apresentados os dados coletados com suas respectivas análises, que permitiram a conclusão desta pesquisa.

\section{RESULTADOS E DISCUSSÃO}

A partir da pesquisa realizada com os contadores do estado de Santa Catarina, puderam-se obter as seguintes análises. Em relação ao perfil dos respondentes, conforme consta na tabela $01,64 \%$ é do sexo Masculino e $36 \%$ do sexo Feminino.

Tabela 01- Gênero dos Respondentes:

\begin{tabular}{l|c|c}
\hline & No & $\%$ \\
\hline Masculino & 203 & $64 \%$ \\
Feminino & 112 & $36 \%$ \\
\hline
\end{tabular}

Fonte: Dados da pesquisa, 2012.

O baixo número feminino ainda é um item preocupante, entretanto nos últimos anos houve uma grande evolução nesse quesito. Segundo dados do CFC, em 2009 o cenário brasileiro de profissionais de contabilidade era composto por $25,6 \%$ de mulheres; atualmente, as mulheres representam $41 \%$ dos profissionais contábeis do Brasil, contabilizando mais de 200 mil profissionais. 
Tabela 02 - Ano de formação:

\begin{tabular}{l|c|c}
\hline & $\mathbf{N}^{\circ}$ & $\%$ \\
\hline De 1965 até 1980 & 14 & $5,19 \%$ \\
De 1981 até 1995 & 61 & $22,59 \%$ \\
De 1996 até 2012 & 195 & $72,22 \%$ \\
\hline
\end{tabular}

Fonte: Dados da pesquisa, 2012.

De acordo com as respostas obtidas (tabela 02), houve um grande crescimento na taxa de formandos em ciências contábeis nos últimos 17 anos, representando mais de $70 \%$ das respostas dos questionários, sendo que 45 $(14,29 \%)$ dos 315 questionários respondidos não continham resposta para esta questão. $\mathrm{O}$ ano que representou a maior quantidade de alunos formados foi o de 2007, com 25, e o ano de 1969, com dois acadêmicos formados, representou o mais antigo. Desde esse ano, apenas 1970 e 1973 não apresentaram alunos formados nessa pesquisa.

Tabela 03 - Idade:

\begin{tabular}{|c|c|c|}
\hline & $\mathbf{N}^{0}$ & $\%$ \\
\hline Menos de 25 anos & 32 & $10 \%$ \\
\hline 26 a 35 anos & 103 & $33 \%$ \\
\hline 36 a 45 anos & 87 & $28 \%$ \\
\hline 46 a 59 anos & 75 & $24 \%$ \\
\hline Mais de 60 anos & 16 & $5 \%$ \\
\hline
\end{tabular}

Fonte: Dados da pesquisa, 2012.

Com o intuito de verificar a faixa etária dos contadores de Santa Catarina, conforme tabela 03 , pode-se perceber que a idade mais encontrada na pesquisa foi entre 26 e 35 anos, compondo 1/3 das respostas. Juntamente com a alternativa "36 a 45 anos" compreendem uma taxa de mais de $60 \%$ dos questionários respondidos, daí a relação do crescente número de formandos na última década, assim como consta na tabela 02. As alternativas "menos de 25 anos" e "mais de 60 anos" foram as menos respondidas, correspondendo respectivamente 10 e $5 \%$ das respostas.

Tabela 04 - Área de atuação:

\begin{tabular}{|c|c|c|}
\hline & $\mathbf{N}^{\circ}$ & $\%$ \\
\hline $\begin{array}{l}\text { Escritório Contábil } \\
\text { Departamento Contábil } \\
\text { Área Acadêmica } \\
\text { Área Pública } \\
\text { Autônomo }\end{array}$ & $\begin{array}{l}141 \\
83 \\
21 \\
37 \\
30\end{array}$ & $\begin{array}{c}45 \% \\
26 \% \\
7 \% \\
12 \% \\
10 \%\end{array}$ \\
\hline
\end{tabular}

Fonte: Dados da pesquisa, 2012. 
Ainda caracterizando os respondentes, com base nos resultados alcançados (tabela 04), pode-se inferir que quase metade dos entrevistados (45\%) trabalha em escritórios contábeis. Área Pública, autônomo e área acadêmica juntos apenas correspondem $29 \%$ das respostas. Esta última amarga a pior posição, com apenas $7 \%$ das respostas.

Em relação à pesquisa acadêmica, perguntou-se: Na sua visão as IFRS contribuem para que haja melhor compreensão e análise das demonstrações contábeis?

Gráfico 01- Contribuição das IFRS:

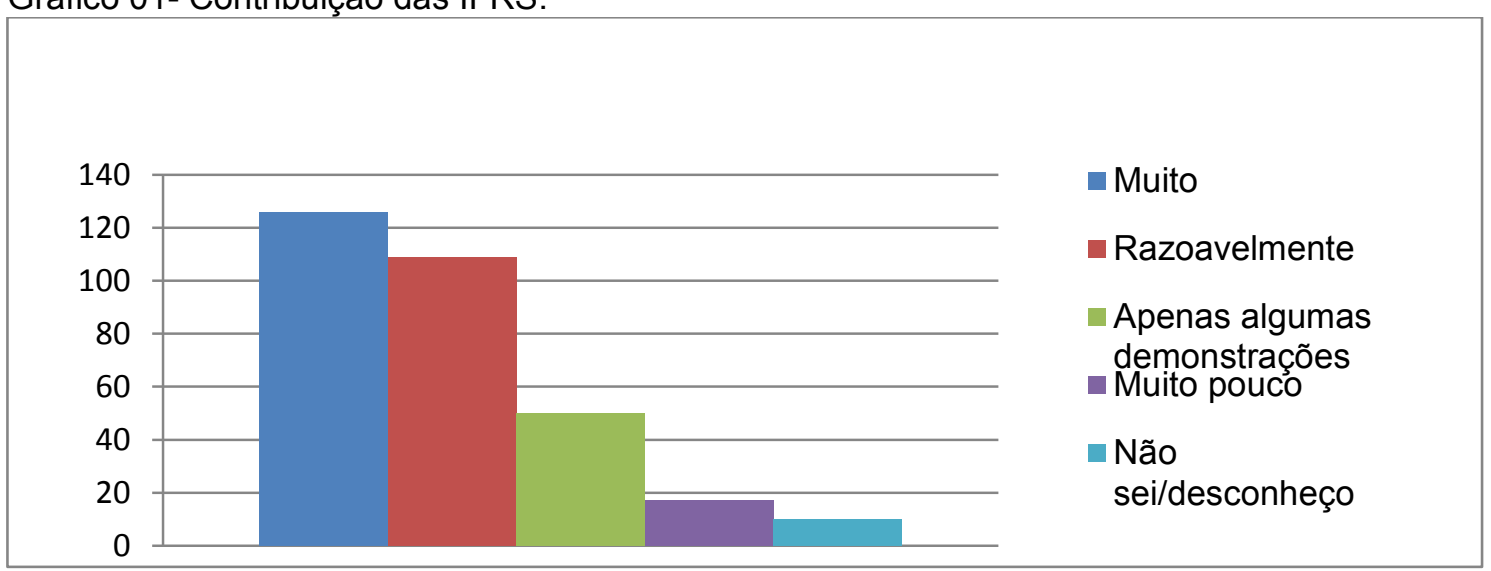

Fonte: Dados da pesquisa, 2012.

Analisando o gráfico 01, é possível concluir que as alternativas "muito" e "razoavelmente" foram as mais lembradas, correspondendo 235 (74,60\%) respostas. Entretanto, o alerta se dá pelo fato de muitas pessoas entenderem que as IFRS pouco contribuem para uma melhor análise e compreensão dos dados contábeis, uma vez que as alternativas "apenas algumas demonstrações", "muito pouco" e "não sei/desconheço" compreenderam $1 / 4$ das respostas.

Em relação aos possíveis investimentos oriundos do exterior, decorrentes da maior facilidade nas relações internacionais graças ao uso de uma linguagem contábil única internacionalmente, perguntou-se: Para você as mudanças decorrentes da homogeneização das demonstrações contábeis são favoráveis para atrair novos investidores? 
Tabela 05 - Favorecimento da atração de Novos Investidores:

\begin{tabular}{l|c|c}
\hline & $\mathbf{N}^{\circ}$ & $\%$ \\
\hline Sim & 266 & $84 \%$ \\
Não & 44 & $14 \%$ \\
\hline
\end{tabular}

Fonte: Dados da pesquisa, 2012

De acordo com a tabela $05,84 \%$ dos profissionais acreditam que a harmonização das IFRS propiciou uma maior atração de investimentos provenientes do exterior; $14 \%$ compreendem que a homogeneização não favoreceu a atração de investimentos internacionais. Cinco pessoas não responderam esta questão.

Ainda destacando a relevância que as IFRS trazem ao cenário contábil brasileiro, perguntou-se: A implantação das IFRS no cenário contábil brasileiro demonstra um avanço para a atividade contábil?

Tabela 06 - Avanço para atividade contábil:

\begin{tabular}{l|l|l}
\hline & $\mathbf{N}^{\circ}$ & $\%$ \\
\hline Um avanço que demonstra a maturidade da ciência contábil & 133 & $42 \%$ \\
Demonstra que o cenário contábil brasileiro está apto para atrair novos investimentos & 124 & $39 \%$ \\
Não demonstra avanço para a atividade contábil & 17 & $5 \%$ \\
A implantação não foi realizada no momento adequado & 36 & $11 \%$ \\
\hline
\end{tabular}
Fonte: Dados da pesquisa, 2012.

Analisando a tabela 06, foi possível perceber que a maioria dos profissionais de contabilidade tem ciência da importância que as IFRS ocasionaram no âmbito contábil brasileiro. Das 310 respostas, 257 (81\%) figuraram entre as alternativas que destacam a maturidade da ciência contábil e a atração de novos investimentos. Entretanto, $5 \%$ dos entrevistados acreditam que as IFRS não demonstram avanço para a contabilidade, e $11 \%$ entendem que a implantação não foi realizada no momento oportuno. 
Gráfico 02 - Grau de conhecimento sobre as Novas Normas Brasileiras de Contabilidade:

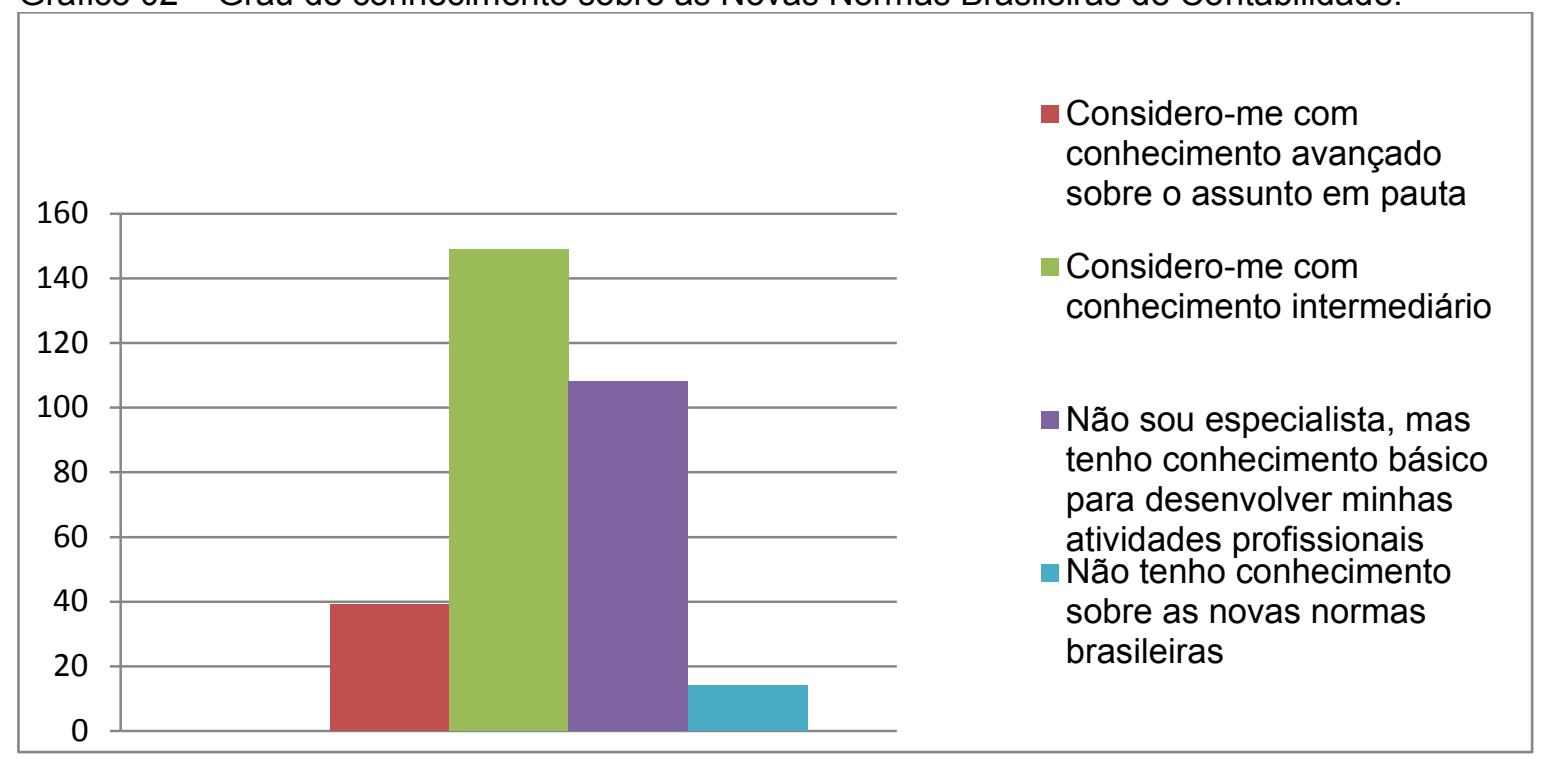

Fonte: Dados da pesquisa, 2012.

Com a finalidade de perceber o grau de atualização e conhecimento dos contadores em relação às novas normas contábeis, foi questionado qual era o nível de informação dos profissionais, como consta no gráfico 02. Analisando o gráfico, compreende-se que grande parte dos profissionais (83\%) figura entre 0 conhecimento intermediário ao conhecimento básico. Apenas $12,60 \%$ dos profissionais apresentam conhecimento avançado, e 4,5\% dos respondentes afirmam não ter conhecimento algum sobre as novas normas brasileiras.

A próxima questão foi elaborada com o propósito de perceber qual a contribuição do Conselho Regional de Contabilidade em relação à atualização do profissional contábil. Perguntou-se: O conselho regional contribui para a atualização profissional em relação às novas normas de contabilidade?

A alternativa mais respondida foi "sim, mas deveria promover com maior rotatividade cursos relacionados às IFRS" com 45\%; 36\% afirmaram que o conselho é atuante e promove cursos de educação que permitem a atualização do profissional; contudo, $18 \%$ dos profissionais afirmaram que o conselho promove poucos cursos ou não fomenta a atualização do contador em referência às novas normas.

Questionando se as novas informações contábeis incorporam maior segurança, perguntou-se: Com a implantação das IFRS, as demonstrações contábeis relatam informações mais fidedignas? 
Gráfico 03 - Fidedignidade das novas demonstrações contábeis:

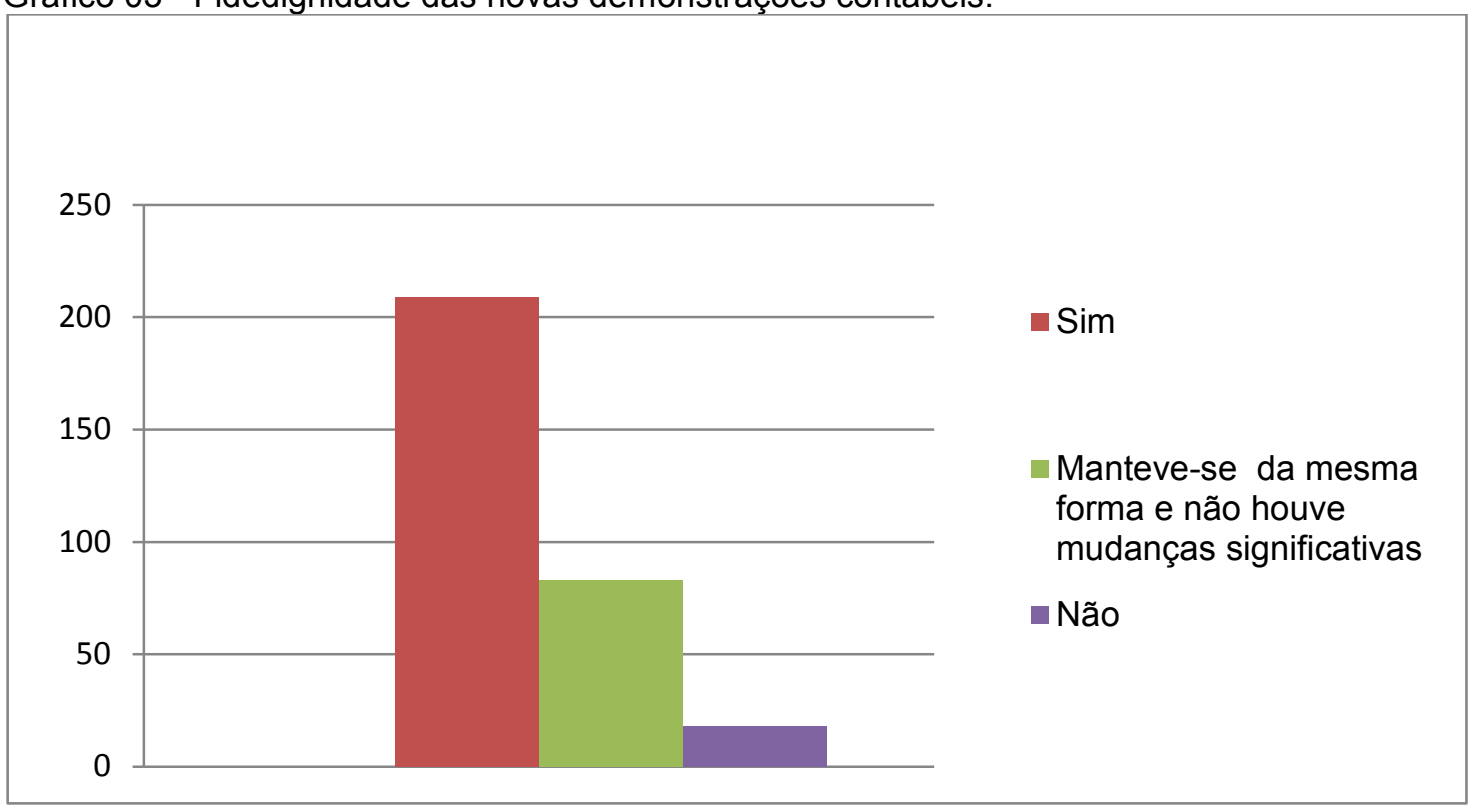

Fonte: Dados da pesquisa, 2012.

Conforme gráfico 03, a resposta "sim" foi a mais respondida, correspondendo $67,42 \%$ dos entrevistados, no entanto, $26,77 \%$ das pessoas compreendem que se manteve da mesma forma, sem qualquer mudança significativa, e 5,81\% consideram que a implantação das IFRS não trouxe maior veracidade aos dados contábeis. As respostas negativas nesta questão demonstram um aspecto a ser dado atenção, uma vez que compreenderam quase $1 / 3(32,58 \%)$ das respostas.

Com a intenção de verificar quais os meios que informatizaram os profissionais de contabilidade sobre as novas normas, questionou-se: Como você obteve informações sobre mudanças ocorridas nas normas contábeis brasileiras trazidas pela lei 11.638/07?

Tabela 07 - Forma de obtenção de informações sobre as novas mudanças contábeis:

\begin{tabular}{l|c|c}
\hline & $\mathbf{N}^{\mathbf{0}}$ & $\%$ \\
\hline Conselho Regional de Contabilidade & 85 & $27 \%$ \\
Mídias Sociais & 39 & $12 \%$ \\
Televisão/rádio & 5 & $2 \%$ \\
Boletim eletrônico & 131 & $42 \%$ \\
Colegas de classe profissional & 51 & $16 \%$ \\
\hline
\end{tabular}

Fonte: Dados da pesquisa, 2012.

Conforme a tabela 07 , percebe-se que muitos profissionais (42\%) obtiveram informações através de boletim eletrônico; $27 \%$ foi comunicado pelo Conselho Ágora: R. Divulg. Cient., v. 18, n. 2, p. 202-221, dez. 2011 (ISSN 2237-9010) 
Regional de Contabilidade, logo acima de colegas de classe profissional, com 16\% das respostas. As mídias sociais e televisão/rádio foram pouco lembradas, correspondendo respectivamente 12 e $2 \%$. A atenção dessa pergunta se deve ao fato de as mídias pouco salientarem mudanças tão significativas no meio contábil.

A última questão foi elaborada no sentido de examinar qual mudança foi considerada mais relevante nas novas normas contábeis.

Tabela 08 - Mudanças mais relevantes com a implantação das Novas Normas Contábeis:

\begin{tabular}{|c|c|c|}
\hline & $\mathrm{N}^{\circ}$ & $\%$ \\
\hline Criação do grupo Intangível & 25 & $8 \%$ \\
\hline Substituição da DOAR pela DFC & 65 & $21 \%$ \\
\hline Permissão para estudo e alteração anual das taxas de depreciação & 49 & $16 \%$ \\
\hline $\begin{array}{l}\text { Exclusão da conta de Lucros Acumulados e obrigatoriedade da destinação do lucro } \\
\text { obtido no final de cada período }\end{array}$ & 30 & $10 \%$ \\
\hline $\begin{array}{l}\text { Subdivisão do Ativo em Ativo Circulante e Ativo Não Circulante e o Passivo em Passivo } \\
\text { Circulante e Passivo Não Circulante }\end{array}$ & 25 & $8 \%$ \\
\hline Possibilidade da realização dos Ajustes de Avaliação Patrimonial & 106 & $34 \%$ \\
\hline Desconheço as mudanças & 7 & $2 \%$ \\
\hline
\end{tabular}

Fonte: Dados da pesquisa, 2012.

De acordo com a tabela 08 , com $34 \%$ das respostas, a mudança mais apontada pelos profissionais foi a possibilidade da realização dos ajustes de avaliação patrimonial. As menos citadas foram a criação do grupo intangível e a subdivisão do Ativo em Ativo Circulante e Ativo Não Circulante e o Passivo em Passivo Circulante e Passivo Não Circulante, ambas com $8 \%$ das respostas. Sete profissionais desconhecem as mudanças.

Com base nas respostas obtidas é possível afirmar que os profissionais contábeis do estado de Santa Catarina veem a harmonização contábil como aspecto evolutivo da atividade, contribuindo para atração de novos investidores e tornando os relatórios contábeis mais fidedignos e próximos da realidade das organizações, colaborando para que o objetivo da ciência contábil seja atingindo.

\section{CONSIDERAÇÕES FINAIS}

Defronte a tantas mudanças ocorridas recentemente na regulamentação contábil, a presente pesquisa procurou analisar qual a percepção dos profissionais 
de contabilidade de Santa Catarina em relação a estas mudanças, além de procurar identificar qual o nível de conhecimento e atualização destes profissionais.

Essas profundas alterações surgiram para adequar a constante divergência contábil entre países, promovendo uma maior interação nas relações internacionais, além de acarretar uma nova ótica na interpretação e análise das demonstrações contábeis. No Brasil, as novas normas vieram com o intuito de estimular maiores investimentos provindos do exterior.

A partir dos resultados obtidos com a pesquisa, pode-se concluir que grande parte dos profissionais tem ciência sobre a existência e importância das novas mudanças da contabilidade. No entanto, muitos julgam as novas normas com certo desleixo. Quando questionado sobre a importância das IFRS nas demonstrações contábeis, $24,68 \%$ dos profissionais ou afirmaram ter relevância em apenas algumas demonstrações, muito pouco, ou desconheciam as novas mudanças. O grau de conhecimento é outro aspecto a ser destacado. Poucos profissionais configuram em um estágio avançado de conhecimento sobre a nova regulamentação contábil. Entretanto ao se perguntar se as novas demonstrações traziam informações mais fidedignas, o percentual de respostas positivas foi alto.

Já no que diz respeito ao aprimoramento do profissional, observa-se que ainda é algo decadente e pouco divulgado. Segundo os dados coletados, mais de $60 \%$ dos respondentes afirmam que o CRC não consegue suprir, ou tem promovido poucos cursos de educação continuada de IFRS para a grande demanda de profissionais.

Com a conclusão desse estudo, percebe-se que diante de mudanças tão significativas no contexto contábil brasileiro e internacional, a taxa de contadores insatisfeitos ou desatualizados sobre as novas regras contábeis ainda é um fator preocupante para a profissão.

Para findar esta pesquisa, sugere-se que sejam realizados novos estudos, que se baseiem em outros métodos de coleta e análise dos dados, procurando investigar a percepção de mais profissionais em diferentes localidades sobre as novas normas contábeis. 


\section{REFÊRENCIAS}

AVELINO, Bruna Camargos et al. Análise do perfil dos estudantes em Ciências Contábeis e sua relação com o processo de convergências das normas contábeis. Revista Brasileira de Contabilidade, Brasília, n. 182, p. 63-77, 2010.

CARVALHO, Dailton Rodrigues de. Contabilista: profissão do presente e do futuro. Disponível em: <http://conthabeis.blogspot.com.br/>. Acesso em: 11 dez. 2012.

COELHO, Cláudio Ulysses Ferreira. O técnico em contabilidade e o mercado de trabalho: contexto histórico, situação atual e perspectivas. Disponível em: <http://www.senac.br/informativo/BTS/263/boltec263d.htm>. Acesso em: 09 dez. 2012.

CHOI, F.D.S e LEVICH, R.M. International capital markets in a world of accounting diversity. In: $\mathrm{CHOI}$; LEVICH. International capital markets in a wold of accounting differences. New York: Irwin, 1994.

COLLIS, J.; HUSSEY, R. Pesquisa em administração: um guia prático para alunos de graduação e pós-graduação. 2. ed. Porto Alegre: Bookmann, 2005.

CONSELHO FEDERAL DE CONTABILIDADE (CFC). Pronunciamentos técnicos contábeis 2008. Disponível em: <http://www.cfc.org.br/uparq/livro_CPC2.pdf>. Acesso em: 10 dez. 2012.

. Resolução CFC no 1.055/05. Disponível em: <http://www.cgu.gov.br/ PrevencaodaCorrupcao/Integridade/IntegridadeEmpresas/arquivos/RES_1055.pdf>. Acesso em: 09 dez. 2012.

. Resolução CFC n 560/83. Disponível em: <http://www.crcsp.org.br/ portal_novo/legislacao_contabil/resolucoes/Res560.htm>. Acesso em: 11/12/2012.

COSTA, Camila Lopes, CAMPOS, Francislaine Mendes de, AMARAL, Marielen Moreira. Capacitação profissional: um estudo sobre a adoção das Normas Internacionais de Contabilidade (IFRS) nas instituições particulares de ensino superior do ABC. Revista Brasileira de Contabilidade, Brasília, n. 177, p. 77-89, 2009.

JUNIOR, Meirelles. Harmonização das Normas Internacionais de Contabilidade. Disponível em: <http://www.aedb.br/seget/artigos09/58_HARMONIZACAO_

DAS_NORMAS_INTERNACIONAIS_DE_CONTABILIDADE.pdf>. Acesso em: 06 dez. 2012.

LUFT, Celso Pedro. Minidicionário Luft. 20.ed. São Paulo: Ática, 2000.

MARION, José Carlos. Contabilidade empresarial. 11. ed. São Paulo: Atlas, 2005. 
MERLO, Roberto Aurélio de. O contabilista do século XXI. Disponível em: <http://www.crcro.org.br/crcmx/principal2.aspx?id2=162>. Acesso em: $11 \mathrm{dez} .2012$.

NAGATSUKA, Divane A. S.; TELES, Egberto L. Manual de contabilidade introdutória. São Paulo: Pioneira Thomson Learning, 2005.

NIYAMA, José Carlos. Análise das demonstrações contábeis. 5.ed. São Paulo: Atlas, 2009.

SÁ, Antônio Lopes de. Novas visões na profissão contábil. Disponível em: <http://www2. masterdirect.com.br/448892/index.asp?opcao=7\&cliente=448892\&avul sa=4999>. Acesso em: 11 dez. 2012.

SÁ, Antônio Lopes de. Realidade sobre normas internacionais de contabilidade. Disponível em: <http://www.administradores.com.br/informe-se/artigos/realidadesobre-normas-internacionais-de-contabilidade/32277/> Acesso em: 11 dez. 2012.

SÁ, Antônio Lopes de. Teoria da contabilidade. 3. ed. São Paulo: Atlas, 2002.

SOUZA, Alan Aparecido Siqueira, COUTINHO FILHO, Fernando Batista.

Harmonização Internacional: um estudo sobre as dificuldades de convergência das normas contábeis brasileiras em relação as normas internacionais de contabilidade (IFRS). Disponível em: <http://www.congressousp.fipecafi.org/artigos72007/ 526.pdf>. Acesso em: 06 dez. 2012.

ZANLUCA, Júlio César. História da contabilidade. Disponível em: $<$ http//www.portaldecontabilidade.com.br/temáticas/historia.htm>. Acesso em: 08 dez. 2012. 